\title{
The influence of high-temperature oxidation on the phase distribution of metal substrate in duplex stainless steel
}

\author{
Minami Matsumoto $^{1}$ (D) $\cdot$ Ken Kimura $^{2} \cdot$ Natsuko Sugiura $^{1}$
}

Received: 31 March 2021 / Revised: 24 June 2021 / Accepted: 27 June 2021 /

Published online: 19 July 2021

(c) The Author(s) 2021

\begin{abstract}
Duplex stainless steels (DSSs), which consist of ferrite and austenite phases, are widely used owing to their high strength and good corrosion resistance. However, the oxidation behavior of DSSs is extremely complicated because they have dual phases. In this study, changes in the scale and the metal substrate during oxidation were investigated. UNS S32101 (Fe-21.5\% Cr-5\% Mn-1.5\% Ni-0.3\% Mo-0.22\%N), which is a typical type of DSS, was annealed at $1473 \mathrm{~K}$ for up to $36 \mathrm{ks}$ in air. The microstructure of UNS S32101 consisted of austenite/ferrite phases, the ratio of which was 50:50 at room temperature. After oxidation, Cr, Mn-oxide formed predominantly. The metal substrate beneath the scale changed mostly to ferrite. In the same region, depletion of $\mathrm{Mn}$ and $\mathrm{N}$ concentrations resulted. The decrease in $\mathrm{Mn}$ was due to the formation of $\mathrm{Cr}$, Mn-oxide. In addition, it was revealed that $\mathrm{N}$ content of the metal substrate decreased due to the formation of $\mathrm{N}_{2}$ gas along with the depletion of $\mathrm{Mn}$. It was assumed that the decrease in $\mathrm{Mn}$ and $\mathrm{N}$, which are austenitestabilized elements, led to an increase in ferrite in the depletion area of $\mathrm{Mn}$ and $\mathrm{N}$. From this result, it was expected that the compositional changes in the $\mathrm{Mn} / \mathrm{N}$ depletion area were caused by the oxidation of steel.
\end{abstract}

Keywords Duplex stainless steel $\cdot$ High-temperature oxidation · Gas chromatography $\cdot$ EPMA $\cdot$ EBSD

Minami Matsumoto

matsumoto.y25.minami@jp.nipponsteel.com

1 Steel Research Laboratories, Nippon Steel Corporation, 20-1 Shintomi, Futtsu, Chiba 293-8511, Japan

2 R \& D Laboratories, Nippon Steel Corporation, 20-1 Shintomi, Futtsu, Chiba 293-8511, Japan 


\section{Introduction}

The application of duplex stainless steels (DSSs), the microstructure of which consists of two phases of austenite and ferrite, is currently increasing in a wide range of productions owing to a reduction of Ni content compared with SUS304 and SUS316L. These alloys have a corrosion resistance similar to that of standard austenitic grades as well as good mechanical properties. The DSSs are classified into four types based on the corrosion resistance: lean, standard, super, and hyper [1]. Above all, the lean-type DSSs that have the same corrosion resistance as AISI304 significantly reduce the high-cost elements such as Ni and Mo. The phase distribution and corrosion resistance are controlled by low-cost elements such as Mn and N.

In the steel manufacturing process, ingots are hot rolled or forged after heating at above $1273 \mathrm{~K}$. During the heating process, thick oxide scales generate on the surface of the ingot. Such oxide scales may affect the post-process. When some oxide scales remain on the steel surface after the de-scaling process prior to rolling, surface defects may occur upon hot rolling [2]. Furthermore, in the case of stainless steels, breakaway oxidation of steels results in the formation of nodules. Oxide nodules are likely to cause surface defects during rolling as well. Problems related to these surface defects may also occur during the forging process. Thus, it is important to understand the oxidation behavior of steels, especially those of stainless steels.

The oxidation behavior of DSSs is complicated owing to their different phases. For example, Jepson et al. reported that the thickness and growth rate of the oxide layer affected the metal substrate before oxidation [3, 4]. During the early stage of oxidation, when $\mathrm{Cr}_{2} \mathrm{O}_{3}$ was generated, the oxide layer above the $\alpha$ phase was thicker than that of the $\gamma$ phase. The oxidation state in which the $\mathrm{Cr}_{2} \mathrm{O}_{3}$ layer acts as a protective layer is called normal oxidation. Furthermore, in the breakaway oxidation state, nodule oxides were also generated above the $\gamma$ phase. They mentioned that these behaviors were caused by the difference in the diffusion rate of $\mathrm{Cr}$ in each phase: The $\gamma$ phase, which has a lower diffusion rate of $\mathrm{Cr}$, is less likely to generate $\mathrm{Cr}_{2} \mathrm{O}_{3}$ than the $\alpha$ phase.

In addition, it was also reported that the surface of the metal substrate changed during oxidation. Ran et al. investigated the oxidation behavior and the metal substrate beneath the scale of $19 \mathrm{Cr}-10 \mathrm{Mn}-0.3 \mathrm{Ni}$ steels, which contained $0.2-0.3$ mass $\% \mathrm{~N}$. They expected that the metal substrate contacting the scale might be changed to the $\alpha$ phase because of the lack of $\gamma$-stabilized elements, such as Mn and N, affected by the oxidation [5, 6]. However, the phase distribution of the metal substrate beneath the scale was observed only by optical microscope, and the composition was not analyzed.

Moreover, Li et al. reported that the metal substrate beneath the scale of $25 \mathrm{Cr}-6 \mathrm{Ni}-3 \mathrm{Mo}-1.5 \mathrm{Mn}-0.24 \mathrm{~N}$ steels changed similarly [7]. However, they expected that it might be changed to the $\gamma$ phase because of the formation of the Cr-depleted area by oxidation. In both cases, they reported that the kinetics (weight gain) was parabolic, and $\mathrm{Cr}_{2} \mathrm{O}_{3}$ and $\mathrm{MnO}$ formed mainly in the oxide 
layer. These oxidation states appeared to be in the normal oxidation state. Similar to Ran et al.'s report, their report showed insufficient evidence for the changes in the composition and the phase fraction of the metal substrate beneath the scale. Therefore, there was no consensus about these change behaviors during the oxidation of DSS.

As mentioned above, the oxidation behavior of DSSs tended to be completely different depending on the steel type, that is, the composition of the steel. However, changes in the metal substrate beneath the scale, such as in the previous studies, have not been quantitatively understood. Thus, in the present study, the oxidation behavior of UNS S32101 (21.5Cr-5Mn-1.5Ni-0.3Mo-0.22N), which is representative of a lean-type DSS, was investigated under a controlled heating time. Oxide scale and the metal substrate beneath the scale were investigated carefully using a metallographic analysis, such as an electron probe microanalyzer (EPMA) and electron back-scattering diffraction (EBSD).

\section{Experimental Procedures}

The UNS S32101 ingot was melted in a vacuum melting furnace. The chemical compositions are summarized in Table 1. The ingot was hot-rolled to a thickness of $6 \mathrm{~mm}$ at $1523 \mathrm{~K}$, followed by annealing in air at $1343 \mathrm{~K}$ for $120 \mathrm{~s}$. Specimens of $6 \mathrm{~mm}$ thick, $20 \mathrm{~mm}$ wide, and $40 \mathrm{~mm}$ long were then cut from the annealed sheet. They were then polished using emery paper of up to \#400 and were finally degreased using acetone. Oxidation was conducted in still air in a tube furnace. The temperature was $1473 \mathrm{~K}$ and the time ranged from 3.6 to $36 \mathrm{ks}$. After annealing, the samples were transferred individually into a lidded container to retrieve all spalled scales and cooled to room temperature in air.

Mass gain due to oxidation was measured using a microbalance at RT. Because the spalled scale was also recovered, in this study, the mass of the spalled scales were measured as well and added to the mass gain of the specimens. The cross sections of some specimens were investigated using an optical microscope and field-emission scanning electron microscope (FE-SEM, JEOL-6500F). For the analysis of the scale and metal substrate beneath it, elemental and phase mapping of some cross sections was conducted using energy-dispersive X-ray spectroscopy (EDS), EPMA (JXA-8530F), and EBSD (JSM-6500F). The OIM system (OIM Analysis, ver. 8) was used for analysis.

Furthermore, vapor species generated from the steel during oxidation were investigated. The experimental flow is illustrated in Fig. 1. Approximately $20 \mathrm{~g}$ of flaky UNS S32101 was used as the test specimen and was heated at $1523 \mathrm{~K}$ in an atmosphere of $20 \mathrm{vol} \% \mathrm{O}_{2}$ mixed with $\mathrm{Ar}$ in a closed infrared furnace. When the test specimen was

Table 1 The chemical compositions of the ingot used in this study (mass\%)

\begin{tabular}{llllllllll}
\hline Steel & $\mathrm{C}$ & $\mathrm{Si}$ & $\mathrm{Mn}$ & $\mathrm{P}$ & $\mathrm{S}$ & $\mathrm{Ni}$ & $\mathrm{Cr}$ & $\mathrm{Mo}$ & $\mathrm{N}$ \\
\hline UNS S32101 & 0.0097 & 0.57 & 5.08 & 0.019 & 0.0008 & 1.48 & 21.50 & 0.29 & 0.222 \\
\hline
\end{tabular}


Fig. 1 Analysis of gasification products during oxidation of UNS S32101: (1) and (2) the gas sampling times

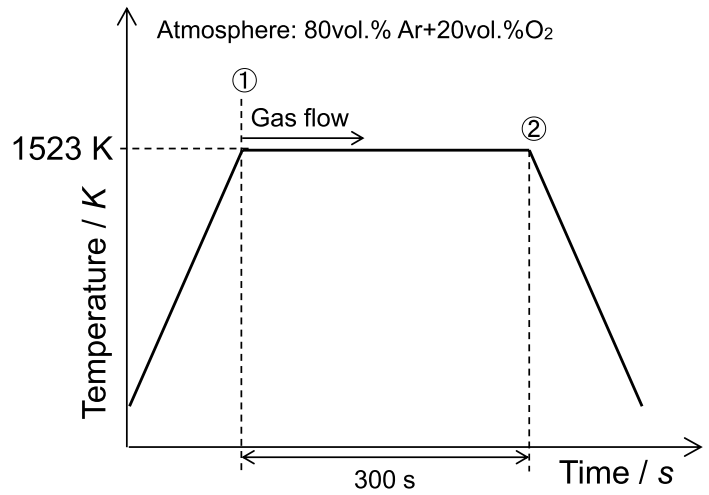

heated for 0 and $300 \mathrm{~s}$, the gas in the furnace was sampled in a tank by changing the direction of the gas flow. The composition of the sampled gas was analyzed using a quadrupole mass spectrometer (Anelva, M-101QA-TDM type).

\section{Results and Discussion}

Figure 2 shows the oxidation kinetics of the steel heated at $1473 \mathrm{~K}$ in air. Because the square of $\Delta w$ was proportional to the oxidation time [8], it behaved parabolic up to the oxidation for $36 \mathrm{ks}$. Therefore, no breakaway oxidation resulted during the current experiment. Cross-sectional back-scattered electron (BSE) images of the scale after heating for $3.6 \mathrm{ks}$ and $36 \mathrm{ks}$ are shown in Fig. 3. The oxide scales which were formed at each heating times were porous. After heating for $3.6 \mathrm{ks}$, a thin oxide scale was formed with a thickness of approximately $10 \mu \mathrm{m}$. The oxide scale grew thicker after heating for $36 \mathrm{ks}$, of approximately $40 \mu \mathrm{m}$. Convolution of the oxide scale was not noticed.

Figure 4 shows the EDS maps for the cross section of the scale heated after 3.6 ks. The scale consisted of $\mathrm{Mn}$ oxide in the outer layer and $\mathrm{Cr}$ oxide in the inner

Fig. 2 Kinetic curves of isothermal oxidation of UNS S32101 at $1473 \mathrm{~K}$ in still air

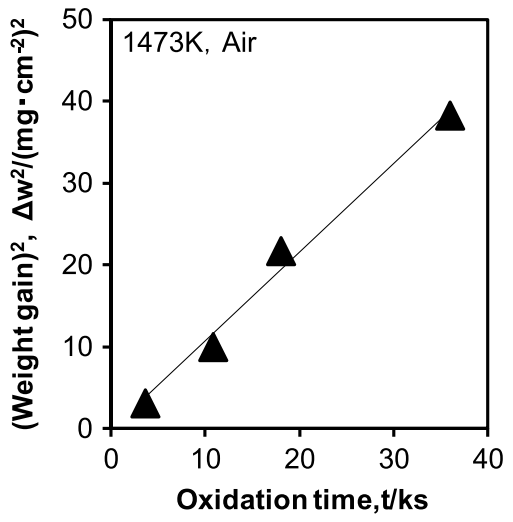




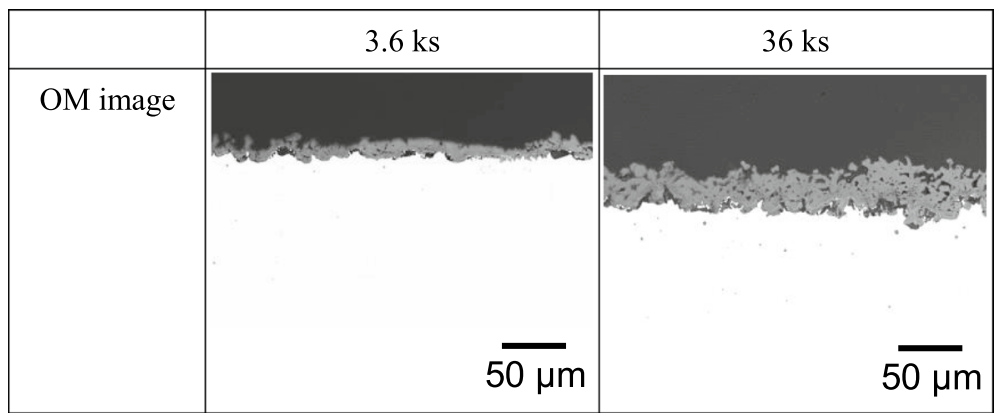

Fig. 3 Cross-sectional BSE images of oxide scales formed at each heating time

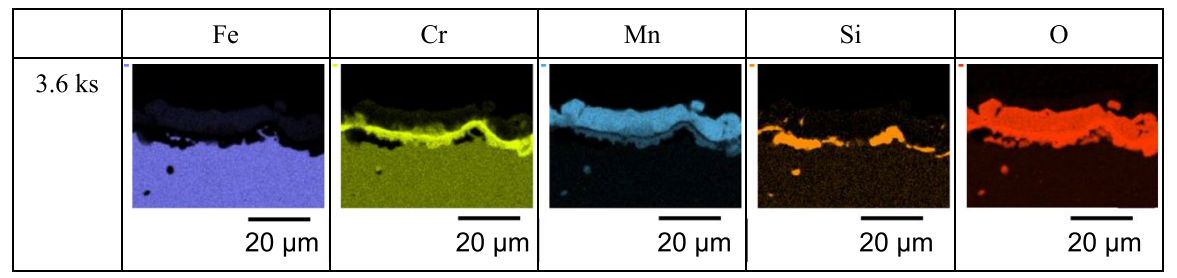

Fig. 4 Cross-sectional EDS images of the specimen heated for $3.6 \mathrm{ks}(\mathrm{Fe}, \mathrm{Cr}, \mathrm{Mn}, \mathrm{Si}, \mathrm{O})$

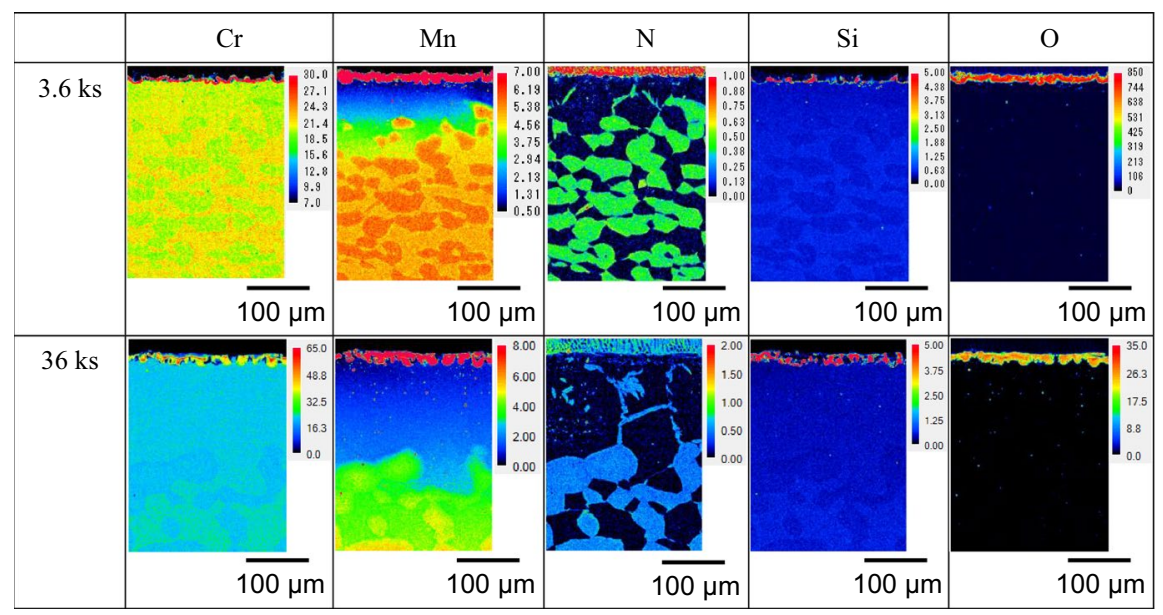

Fig. 5 Cross-sectional EPMA images of the specimen heated for 3.6 and $36 \mathrm{ks}$ (Cr, Mn, N, Si, O)

layer. In addition, Si oxide was observed in the innermost layer of the scale discontinuously. The EDS of the specimen heated for $36 \mathrm{ks}$ was also investigated, and its scale structure profile was almost the same as that of the 3.6-ks heated specimen.

Figure 5 shows the EPMA maps for the cross section of the scale and the metal substrate heated after 3.6 and $36 \mathrm{ks}$. At both heating times, decrease in Mn and N concentration was prominent in the metal substrate beneath the scale. The depth of the 
$\mathrm{Mn}$ and $\mathrm{N}$ depletion area extended with the heating time from approximately $50 \mu \mathrm{m}$ at $3.6 \mathrm{ks}$, to $200 \mu \mathrm{m}$ at $36 \mathrm{ks}$. From the quantitative analysis, the composition of the $\alpha$ phase region inside the metal substrate was $22.5 \mathrm{Cr}-4.9 \mathrm{Mn}-1.2 \mathrm{Ni}-0.6 \mathrm{Si}-0.01 \mathrm{~N}$, and that of the $\gamma$ phase region was $20.9 \mathrm{Cr}-5.6 \mathrm{Mn}-1.7 \mathrm{Ni}-0.6 \mathrm{Si}-0.48 \mathrm{~N}$. At the greatest areas facing the oxide scale, concentrations of $\mathrm{Mn}$ and $\mathrm{N}$ reduced. The $\mathrm{Mn}$ decreased from 5.1 to 0.5 mass $\%$ at minimum, and $\mathrm{N}$ decreased from 0.22 to 0.08 mass\% at minimum. However, $\mathrm{Cr}$ depletion was not clear. The $\mathrm{Cr}$ concentration beneath the scale was 20.5 mass\% compared to the base metal composition of 21.5 mass $\%$.

Figure 6 shows cross-sectional EBSD maps of the specimens. In the polished specimen, the phase fraction of $\alpha$ to $\gamma$ phase of the metal surface was approximately 1:1, similar to the inside area of the specimen. However, the surface of the specimens after oxidation of 3.6 and $36 \mathrm{ks}$ changed to a single $\alpha$ phase and its area expanded with the heating time. The area of the $\alpha$ phase was approximately $50 \mu \mathrm{m}$ thick for the specimens heated for $3.6 \mathrm{ks}$ and $200 \mu \mathrm{m}$ heated for $36 \mathrm{ks}$. These regions corresponded to the $\mathrm{Mn}$ and $\mathrm{N}$ depletion areas shown in Fig. 5.

Based on the above experimental results, the relationship between the oxidation behavior of DSS and changes in the metal substrate beneath the scale was considered. The results from this experiment show that the oxidation of UNS S32101 caused a $\mathrm{Mn}$ and $\mathrm{N}$ decrease in the metal substrate beneath the scale. In the same region, the phase distribution changed to a single $\alpha$ phase. These results are similar to those reported by Ran et al.

It is clear that the decreased Mn concentration is attributed solely to the oxidation because Mn enrichment was found in the outermost oxide scale, as shown in Fig. 4. However, it was unclear why the $\mathrm{N}$ concentration of the metal substrate decreased at the same time. $\mathrm{N}$ is added to the alloy as a $\gamma$-stabilized element and is dissolved by adding $\mathrm{Cr}$ and $\mathrm{Mn}$ [9]. Therefore, it is suggested that the decrease in $\mathrm{N}$ concentration is affected by the decrease in $\mathrm{Mn}$ due to oxidation. Figure 7 shows the calculated results of the phase fractional changes with the Mn concentration of UNS S32101 around the heating temperature by Thermo-Calc. As shown in Fig. 7a, at the heating temperature of $1473 \mathrm{~K}$, the

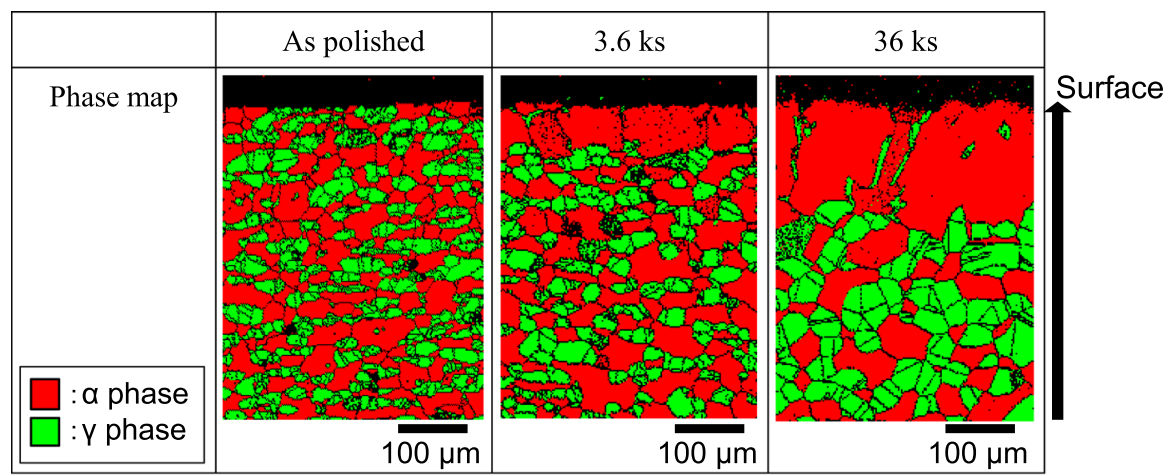

Fig. 6 Phase maps with EBSD of the specimen as polished (before oxidation), heated for 3.6 and $36 \mathrm{ks}$ 
(a)

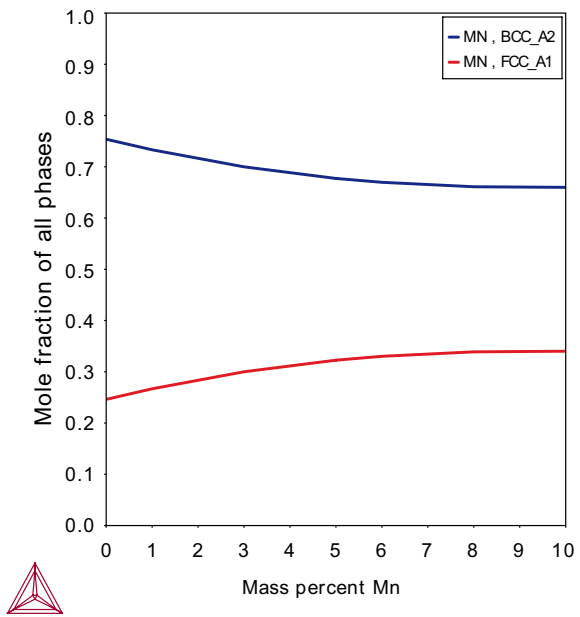

(b)

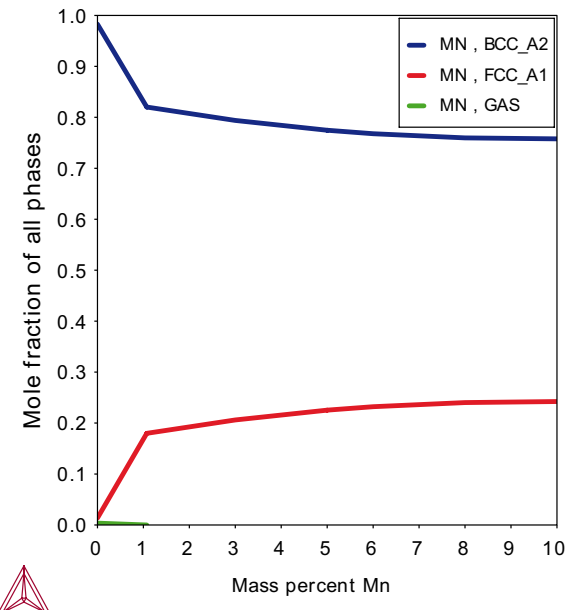

\section{(c)}

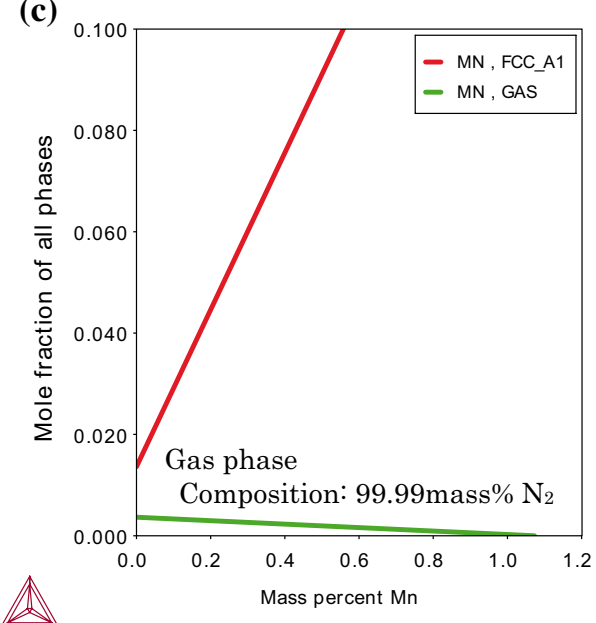

Fig. 7 Effect of amount of Mn on phase fraction: calculation results by Thermo-Calc a at $1473 \mathrm{~K}$, b at $1523 \mathrm{~K}$, and $\mathbf{c}$ enlarged diagram of gas phase $(21.5 \mathrm{Cr}-5 \mathrm{Mn}-1.5 \mathrm{Ni}-0.6 \mathrm{Si}-0.22 \mathrm{~N}-0.01 \mathrm{C}, 1 \mathrm{~atm}, \mathrm{DB}$ : FeDT6)

phase fraction did not change even if the Mn concentration decreased. In general, it is known that the temperature of the oxidized metal surface becomes higher than the atmospheric temperature. Therefore, it was calculated at $1523 \mathrm{~K}$ which is $50 \mathrm{~K}$ higher than the heating temperature as shown in Fig. 7b. The mole fraction of the $\gamma$ phase decreased gradually with decreasing the Mn concentration from 5 to 1 mass\%. From the above results, it is considered that the change in phase fraction beneath the scale as calculated by Fig. $7 \mathrm{~b}$ occurred because the temperature of the metal surface has risen above the atmospheric temperature due to the 
Fig. 8 Gibbs free energy formed by each oxide [Ellingham diagram] (1 atm, DB: Thermo-Calc 2019a)

Fig. 9 The amount of $\alpha$ phase at each depth calculated from the phase map
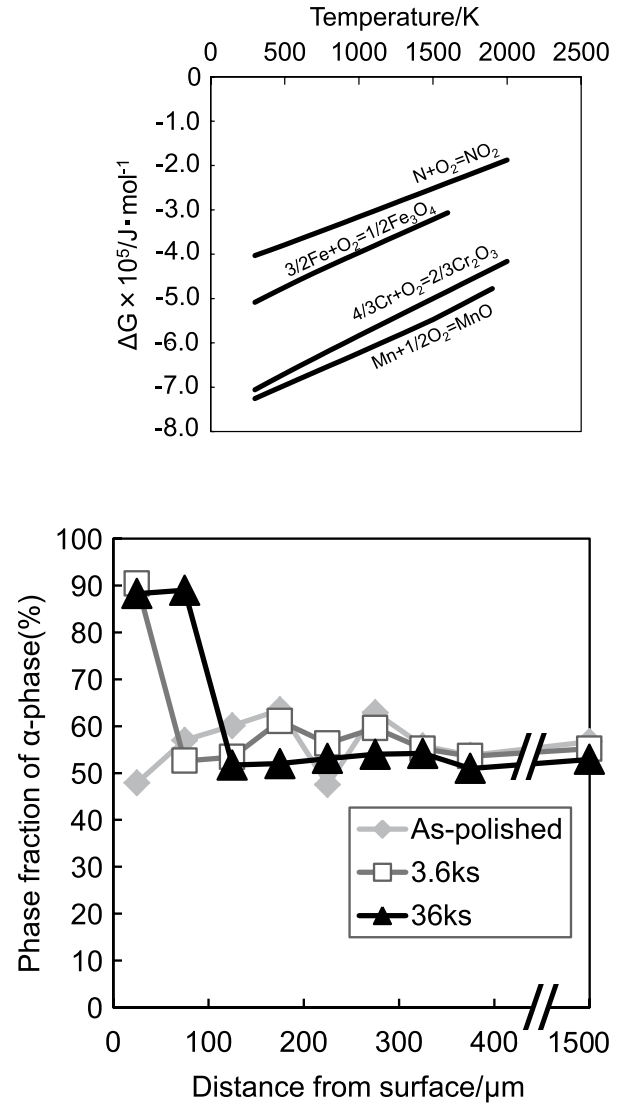

oxidation. Furthermore, it is worth noting that the ratio of the $\gamma$ phase decreased rapidly when the Mn concentration became lower than 1 mass\%. Figure 7c shows an enlarged diagram of the region where the Mn concentration is $1.0 \%$ or less. As shown in Fig. 6c, formation of a gas phase consisting mostly of $\mathrm{N}$ became prominent in this region because $\mathrm{N}$ can no longer be dissolved.

As the experimental and calculation results by Thermo-Calc showed, it is reasonable to consider that the amount of $\mathrm{N}$ dissolved in this metal substrate decreased with the decrease in Mn caused by the oxidation. Ran et al. suggested that the decrease in dissolved $\mathrm{N}$ occurred owing to the oxidation of itself. However, the Ellingham diagrams shown in Fig. 8 indicate that the $\mathrm{N}$ oxides (ex. $\mathrm{NO}, \mathrm{NO}_{2}$ ) are less stable than those of $\mathrm{Cr}$ and $\mathrm{Mn}$ oxides; thus, it is difficult to consider that the dissolved $\mathrm{N}$ is released in air upon oxidation. Furthermore, it is also possible that the dissolved $\mathrm{N}$ diffuses inward into the steel. To quantitatively examine this point, phase fraction of the $\alpha$ phase was calculated from EBSD images shown in Fig. 9. The amount of the $\alpha$ phase in the inner steel did not change after heating for 3.6 and $36 \mathrm{ks}$. It is suggested that the dissolved $\mathrm{N}$ did not diffuse inward into the steel. 


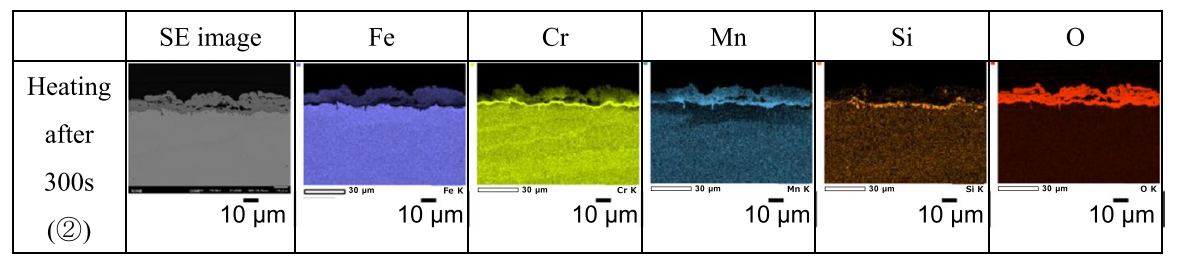

Fig. 10 Cross-sectional SEM and EDS images of the specimen heated after $300 \mathrm{~s}(\mathrm{Fe}, \mathrm{Cr}, \mathrm{Mn}, \mathrm{Si}, \mathrm{O})$

Table 2 Composition of collected gas by mass spectrometry (vol\%)

\begin{tabular}{llll}
\hline $\begin{array}{l}\text { Molecular weight } \\
(\mathrm{m} / \mathrm{z})\end{array}$ & Molecule & \multicolumn{2}{l}{ Heating time } \\
\cline { 3 - 4 } & & (1) $0 \mathrm{~s}$ & (2) $300 \mathrm{~s}$ \\
\hline 28 & $\mathrm{~N}_{2}$ or/and CO & 0.35 & 9.1 \\
30 & $\mathrm{NO}$ & - & - \\
32 & $\mathrm{O}_{2}$ & 14 & 13 \\
40 & $\mathrm{Ar}$ & 86 & 78 \\
44 & $\mathrm{CO}_{2}$ & 0.21 & 0.21 \\
46 & $\mathrm{NO}_{2}$ & - & - \\
\hline
\end{tabular}

Therefore, it is highly possible that dissolved $\mathrm{N}$ diffuses out of the metal substrate as $\mathrm{N}_{2}$ gas. If this outgassing behavior occurs, $\mathrm{N}_{2}$ gas generated from the metal phase must pass through the dense $\mathrm{Cr}$, Mn-oxide. Indeed, such behavior was documented in some oxide system. In the case of low-alloy steel, Kondo et al. reported that the gas permeability depends on the type of scale structure consisting of Fe. Oxides of $\mathrm{FeO}$ and $\mathrm{Fe}_{3} \mathrm{O}_{4}$ have gas permeability, but $\mathrm{Fe}_{2} \mathrm{O}_{3}$ does not [10]. However, it is unknown whether the gas permeability of the scale depends on its composition such as $\mathrm{Cr}_{2} \mathrm{O}_{3}$ and $\mathrm{MnO}$. Therefore, the gassing behavior at UNS S32101 was verified by collecting and analyzing the gas released during oxidation. Since it was focused on the analysis of the released gas in this experiment, this oxidation test was conducted at $1523 \mathrm{~K}$ in order to increase the amount of gas collected.

First, the composition of the scale formed on the specimen after heating for 300 $\mathrm{s}$ was investigated. The results are presented in Fig. 10. Similar to the results shown in Fig. 2, some voids were found in the scale. The scale composed of $\mathrm{Cr}$, Mn-oxide, and the Mn concentration decreased in the metal substrate beneath the scale. Gas analysis collected at each heating time is shown in Table 2. Here, $\mathrm{N}_{2}$ or CO with a molecular weight of 28 and $\mathrm{CO}_{2}$ with a molecular weight of 44 were detected in addition to $\mathrm{Ar}$ and $\mathrm{O}_{2}$ flow gases. A molecule with a weight of 28 occupied $0.35 \mathrm{vol} \%$ of the 0 -s heating gas and $9.1 \mathrm{vol} \%$ of the 300 -s heating gas, which was a 26-fold increase. If the molecular weight of 28 corresponds to $\mathrm{CO}, \mathrm{CO}_{2}$ should also increase upon heating. However, $\mathrm{CO}_{2}$ concentration did not change after heating. Therefore, it is considered that this molecule with a weight of 28 was mainly $\mathrm{N}_{2}$. These results revealed that $\mathrm{N}$ contained in the metal substrate beneath the scale was released as $\mathrm{N}_{2}$ gas to the ambient gas atmosphere and that this behavior caused the 
depletion of N. From the above results, in the UNS S32101, it is clear that the metal substrate beneath the scale has changed to a $\alpha$ single phase because of the oxidation of $\mathrm{Mn}$ and the release of $\mathrm{N}$ as $\mathrm{N}_{2}$ gas during oxidation. It is considered that the scale became porous as shown by Figs. 2 and 10 due to this gassing behavior. It was revealed experimentally for the first time that the depletion area of $\mathrm{Mn}$ and $\mathrm{N}$ was formed and dissolved $\mathrm{N}$ was released as $\mathrm{N}_{2}$ gas, not oxidized as Ran et al. stated.

The results reported by $\mathrm{Li}$ et al. were completely different from those reported in this study and by Ran et al. In a case in which $\mathrm{Cr}_{2} \mathrm{O}_{3}$ scale forms, Li et al. reported that a $\mathrm{Cr}$ depletion area is formed at the metal surface. However, this was not indicated in the present study. Moreover, the phase fraction of the metal substrate beneath the scale also differed. The steel used by Li et al. was stabilized by $\mathrm{Cr}$ in the $\alpha$ phase and $\mathrm{Ni}$ in the $\gamma$ phase. When $\mathrm{Cr}$ depletion occurred through the oxidation, it was expected that the $\gamma$ phase stabilized at the metal substrate because of the relative increase in $\mathrm{Ni}$ concentration, as previously reported. Because the diffusion rate of $\mathrm{Cr}$ in the $\gamma$ phase is slower than that in the $\alpha$ phase [11], it is known that the $\mathrm{Cr}$ depletion area beneath the scale is more likely to be formed in the $\gamma$ phase than in the $\alpha$ phase. Similar to this study, it is considered that the $\mathrm{Cr}$ depletion area was formed in the steel examined by Li et al. By contrast, the steel used in our study and by Ran et al. was stabilized by Mn for the $\gamma$ phase and the metal substrate beneath the scale was changed to the $\alpha$ phase by the decrease in Mn during oxidation (as shown in Figs. 4 and 5). As mentioned above, it is considered that $\mathrm{Cr}$ depletion did not occur in this study because of the higher diffusion rate of $\mathrm{Cr}$ in the $\alpha$ phase. If the above considerations are correct, Mn depletion area should be not formed for the same as Cr. However, Mn depletion was observed in this study. It is considered that the composition and diffusion rate are different between $\mathrm{Cr}$ and $\mathrm{Mn}$. The diffusion rate of $\mathrm{Mn}$ is slower than that of $\mathrm{Cr}$ in the $\alpha$ phase [11], and the composition of $\mathrm{Mn}$ is approximately $1 / 10$ of $\mathrm{Cr}$. Moreover, it was expected that $\mathrm{Mn}$ dissolved in the steel will generate more oxides than $\mathrm{Cr}$. Inoue et al. reported that oxidized $\mathrm{Mn}\left(\mathrm{Mn}^{2+}\right)$ has a higher diffusion rate in $\mathrm{Cr}_{2} \mathrm{O}_{3}$ [12]. From the above consideration, it was speculated that the change in phase fraction beneath the scale could occur depending on the ease of oxidation of the $\gamma$-stabilized element.

\section{Summary}

The oxidation behavior and changes in the metal substrate beneath the scale at UNS S32101, classified as DSSs, were investigated. Under the heating conditions of this study, uniform formation of $\mathrm{Cr}$, Mn-oxide resulted, along with the formation of area of exclusive $\alpha$ phase in the metal substrate beneath the scale. This was attributed to the depletion of $\mathrm{Mn}$ and N. Furthermore, this region increased with increasing the heating time. It was found that the decrease in Mn was caused by its oxidization, which accompanied a decrease in the amount of $\mathrm{N}$ composition. Furthermore, it was experimentally clarified that $\mathrm{N}$, which could not be dissolved in the metal substrate, permeated through the $\mathrm{Cr}$, Mn-oxide and was released as $\mathrm{N}_{2}$ gas into the ambient gas atmosphere. It was expected that changes in the phase fraction of the 
metal substrate beneath the scale depend on the phase stability of the oxidized elements. In this study, we investigated the oxidation behavior where breakaway oxidation did not take place. In case where breakaway oxidation takes place, additional studies are needed.

Acknowledgements The author wishes to thank T. Murasawa and A. Hashimoto for their contribution in conducting the laboratory experiments. And we are grateful to Prof. K. Ushioda and Dr. N. Otsuka for helpful discussions.

Authors' contributions All authors contributed to the study conception and design. Material preparation, data collection and analysis were performed by MM, KK and NS. The first draft of the manuscript was written by Minami Matsumoto, and all authors commented on previous versions of the manuscript. All authors read and approved the final manuscript.

Funding Not applicable.

Availability of data and material All authors make sure that all data and materials as well as software application support their published claims and comply with field standards.

\section{Declaration}

Conflict of interest All authors declare that they have no conflict of interest.

Open Access This article is licensed under a Creative Commons Attribution 4.0 International License, which permits use, sharing, adaptation, distribution and reproduction in any medium or format, as long as you give appropriate credit to the original author(s) and the source, provide a link to the Creative Commons licence, and indicate if changes were made. The images or other third party material in this article are included in the article's Creative Commons licence, unless indicated otherwise in a credit line to the material. If material is not included in the article's Creative Commons licence and your intended use is not permitted by statutory regulation or exceeds the permitted use, you will need to obtain permission directly from the copyright holder. To view a copy of this licence, visit http://creativecommons.org/licen ses/by/4.0\%.

\section{References}

1. H. Kajimura, Bulletin of the Iron and Steel Institute of Japan 20, 621 (2015).

2. M. Krzyzanowski, J. H. Beynon, D. C. J. Farrugia. Oxide Scale Behavior in High Temperature Metal Processing (Wiley-VCH, 2010).

3. M. A. E. Jepson and R. L. Higginson, Corrosion Science 59, 263 (2012).

4. M. A. E. Jepson and R. L. Higginson, Corrosion Science 51, 588-594 (2009).

5. Q. Ran, Q. Liu, Y. Xu, et al., Corrosion Science 98, 737 (2015).

6. Q. Ran, W. Peng, Y. Xu, et al., Corrosion Science 90, 535-543 (2015).

7. L. F. Li, Z. H. Jiang, and Y. Riquier, Corrosion Science 47, 57-68 (2005).

8. D. J. Young, High Temperature Oxidation and Corrosion of Metals (Elsevier, 2016).

9. Y. Imai, Influences of Nitrogen on Some Properties of Iron and Steel (AGNE Gijutsu Center, 1994)

10. Y. Kondo, H. Tanei, K. Ushioda, and M. Maeda, ISIJ International 52, 2254 (2012).

11. R. E. Lobnig, H. P. Schmidt, K. Hennesen, and H. J. Grabke, Oxidation of Metals 37, 81 (1992).

12. Y. Inoue, N. Hiraide, A. Hayashi, and K. Ushioda, Tetsu-to-Hagané 103, 184 (2017).

Publisher's Note Springer Nature remains neutral with regard to jurisdictional claims in published maps and institutional affiliations. 